\title{
Appetite suppressants and valvular heart disease - a systematic review
}

\author{
Yoon K Loke*, Sheena Derry and Angharad Pritchard-Copley
}

Address: Department of Clinical Pharmacology, University of Oxford, Radcliffe Infirmary, Oxford OX2 6HE, United Kingdom

E-mail: Yoon K Loke* - yoon.loke@clinpharm.ox.ac.uk; Sheena Derry - sheena.derry@clinpharm.ox.ac.uk; Angharad PritchardCopley - a_pritchard_copley@hotmail.com

${ }^{*}$ Corresponding author

Published: 23 August 2002

BMC Clinical Pharmacology 2002, 2:6

This article is available from: http://www.biomedcentral.com//472-6904/2/6

(C) 2002 Loke et al; licensee BioMed Central Ltd. This article is published in Open Access: verbatim copying and redistribution of this article are permitted in all media for any non-commercial purpose, provided this notice is preserved along with the article's original URL.
Received: 21 June 2002

Accepted: 23 August 2002

\begin{abstract}
Background: Although appetite suppressants have been implicated in the development of valvular heart disease, the exact level of risk is still uncertain. Initial studies suggested that as many as I in 3 exposed patients were affected, but subsequent research has yielded substantially different figures. Our objective was to systematically assess the risk of valvular heart disease with appetite suppressants.
\end{abstract}

Methods: We accepted studies involving obese patients treated with any of the following appetite suppressants: fenfluramine, dexfenfluramine, and phentermine. Three types of studies were reviewed: controlled and uncontrolled observational studies, and randomized controlled trials. Outcomes of interest were echocardiographically detectable aortic regurgitation of mild or greater severity, or mitral regurgitation of moderate or greater severity.

Results: Of the 1279 patients evaluated in seven uncontrolled cohort studies, 236 (18\%) and 60 (5\%) were found to have aortic and mitral regurgitation, respectively. Pooled data from six controlled cohort studies yielded, for aortic regurgitation, a relative risk ratio of 2.32 (95\% confidence intervals 1.79 to $3.01, \mathrm{p}<0.0000 \mathrm{I}$ ) and an attributable rate of $4.9 \%$, and for mitral regurgitation, a relative risk ratio of $1.55(95 \%$ confidence intervals 1.06 to $2.25, p=0.02)$ with an attributable rate of $1.0 \%$. Only one case of valvular heart disease was detected in 57 randomized controlled trials, but this was judged unrelated to drug therapy.

Conclusions: The risk of valvular heart disease is significantly increased by the appetite suppressants reviewed here. Nevertheless, when considering all the evidence, valvulopathy is much less common than suggested by the initial, less methodologically rigorous studies.

\section{Background}

The first case reports that suggested a link between the use of appetite suppressants and valvular heart disease were published in 1997.[1] These initial reports were followed by a US Food and Drug Administration (FDA) echocardiographic survey, which found valvulopathy in $32.8 \%$ of
284 subjects who had been taking appetite suppressants.[2] Since then, other researchers have performed similar echocardiographic studies, some of which have included control obese patients unexposed to appetite suppressants. The rate of valvulopathy in these later studies appears to be considerably lower than that of the original 
FDA survey, and there is now debate as to the exact risk.[3] In view of this uncertainty, we decided to perform a systematic review of the published evidence.

\section{Methods}

The review was conducted according to a defined protocol.

\section{Data sources}

We used a sensitive search string for the following electronic databases:

MEDLINE 1966-September 2001 - [phentermine or fenfluramine or dexfenfluramine] and [(stud* or trial*) or (valv* or aortic or mitral) or (case-control-studies or cohort-studies or \{clinical-trial in pt\}) or (phentermine/adverse-effects or fenfluramine/adverse-effects or dexfenfluramine/adverse-effects)] and [human in tg].

EMBASE 1980-Septemebr 2001 - [phentermine or fenfluramine or dexfenfluramine] and [(stud* or trial*) or (valv* or aortic or mitral) or ( $\{$ case-control-study or cohort-analysis or clinical-trial $\}$ in der) or (phentermine/adverse-drug-reaction or fenfluramine/adverse-drugreaction or dexfenfluramine/adverse-drug-reaction)] and [human in der].

The search was performed independently by each of the authors. Relevant studies were identified through a combination of electronic searching and manual checking of reference lists from previous review papers. We applied no language restrictions.

\section{Study selection}

Studies: The following types were examined:

1) randomized, controlled trials with placebo or no treatment control groups.

2) observational studies evaluating the risk of valvulopathy.

Reports were included if they were full journal publications; we excluded abstracts, letters, review articles and case reports. We contacted authors when specific aspects of the published data required clarification.

Participants: We included studies that involved adult, obese patients treated with appetite suppressants. In order to maximize the likelihood of detecting adverse events, we only accepted studies that involved at least 10 participants.

Intervention: The appetite suppressants of interest were dexfenfluramine, fenfluramine and phentermine. We ac- cepted studies where any of the three agents were used, alone or in combination, for at least one month. Crossover studies were excluded.

Outcome Measures: The events of interest were echocardiographically detectable aortic and mitral regurgitation. We looked specifically for reports of valvulopathy that met FDA case definitions, i.e. aortic regurgitation of mild or greater severity (FDA AR), or mitral regurgitation of moderate or greater severity (FDA MR).

\section{Data extraction}

Appraisal of Study Quality and Data Abstraction: We did not anonymize the reports before assessment. All potentially relevant studies were checked independently by the reviewers, using a predetermined protocol, to determine eligibility for inclusion and to extract data. A list of studies that were excluded is available from the authors.

We recorded the numbers and severity of any valvular lesions. We also sought information on participants, blinding, type of control, drug exposure, nature of follow-up, and methods or criteria used in diagnosing valvulopathy. Components of quality assessment for the randomized controlled trials were concealment of allocation sequence, blinding, and reporting of withdrawals. For the observational studies, we evaluated the methods of patient selection and blinding of outcome assessors.

Any discrepancies were resolved by discussion.

\section{Data synthesis}

The numbers of patients with valvulopathy in the uncontrolled studies were simply added up to calculate the overall rate from the total number of patients who underwent echocardiography.

For the controlled studies, pooled relative risk ratios and heterogeneity were analysed using RevMan 4.1. We used the fixed effects model in calculating the pooled relative risk ratios. The number needed to harm (NNH), with $95 \%$ confidence intervals (95\% CI), was calculated by applying the calculated relative risk ratio to the pooled control event rate.

\section{Results}

The search strategy yielded 2400 hits in total. On checking the electronic records, 1729 clearly failed to satisfy one or more of the inclusion criteria, leaving 671 potentially relevant papers for more detailed evaluation. From these, we accepted 57 randomized controlled trials and 14 observational echocardiographic studies. Principal reasons for exclusion were: review article, case report, drug not used in management of obese participants, clinical trial not randomized or controlled, echocardiographic grade of valvu- 
Table I: Summary of characteristics of the randomized controlled trials analysed

\begin{tabular}{ll}
\hline Trials & No. of trials \\
\hline & \\
- Placebo controlled & 52 \\
- No treatment controls & 5 \\
Blinding & \\
- Single blind & 2 \\
- Double blind & 46 \\
Drugs used and dosage & \\
Dexfenfluramine 10-80 mg/day (mostly & 35 \\
30 mg) & 7 \\
Phentermine 30 mg/day & 11 \\
Fenfluramine $40-160$ mg/day & 4 \\
Phentermine-fenfluramine $30-60$ mg/day & 17 weeks \\
Mean duration & $4-60$ weeks \\
Range & \\
Information on Adverse effects & 47 \\
Monitored for any adverse effects & 41 \\
Gave details of adverse effects & 15 \\
No details of any adverse effects & $\underline{\text { No. }}$ \\
Patients & 2907 \\
- Treated & 2252 \\
- Control & 43 \\
- Mean age & $77 \%$ female \\
- Sex & \\
Cases of valvular heart disease & 1 (but judged unrelated \\
\hline Treated & to treatment) \\
Controls & 0 \\
\hline
\end{tabular}

lopathy not reported in observational study. We did not find any case-control studies that evaluated the link between valvulopathy and appetite suppressants.

We identified 57 randomized controlled trials, involving over 5100 participants, that fulfilled our criteria. The main features of the trials are summarized in Table 1 (details of individual trials are available from the authors). Cardiac echocardiography was not routinely performed in any of the trials, although monitoring of adverse events was specifically mentioned in 47 trials. Only one case of valvular heart disease was noted among the 41 trials that reported adverse effects. The patient had mitral regurgitation which was judged to be due to myocardial infarction rather than drug therapy.

There were seven uncontrolled echocardiographic surveys available for analysis (Table 2). [2,4-9] Overall, a total of 236 cases $(18 \%)$ with FDA AR, and $58(5 \%)$ with FDA MR were detected in the 1279 patients evaluated. There were considerable differences in the design of these seven studies, with particular regard to patient selection and blinding of the outcome assessors. This may have accounted for the variation in the number of cases detected - for example, FDA AR rates ranged from $6 \%$ to $29 \%$. Nevertheless, these figures suggest that more than 1 in 5 patients taking appetite suppressants were at risk of developing valvulopathy.

We found seven controlled echocardiographic studies that evaluated the risk of valvulopathy in 5200 obese individuals (Table 3).[10-16] Most of the participants were middle-aged women. Overall, FDA AR was found in $9.7 \%$ of those taking appetite suppressants, and in $3.5 \%$ of controls (Figure 1). The pooled relative risk ratio for FDA AR was 2.82 (95\% CI 2.20 to $3.61, \mathrm{p}<0.00001)$ with a number needed to harm of 16 (95\% CI 11 to 24). Data on severe aortic regurgitation was reported in six studies, with a pooled rate of $7 / 3045(0.23 \%)$ in the exposed group and $4 / 1825(0.22 \%)$ in the control group.

There was significant heterogeneity in the analysis of FDA $\operatorname{AR}\left(\chi^{2} 16.0, p=0.01\right)$. As seen from the Forrest plot (Figure 1), this was accounted for by Khan's study [13] in which the relative risk for FDA AR was 17.0, a figure which is several times above that obtained from the other studies. When Khan's study was excluded from the meta-analysis, there was no evidence of significant heterogeneity. In this revised analysis (Figure 2), the relative risk for FDA AR was $2.32(95 \%$ CI 1.79 to $3.01, \mathrm{p}<0.00001)$, with a number needed to harm of 20 (95\% CI 13 to 33 ).

FDA MR was much less common than FDA AR; it was found in $2.9 \%$ of those exposed to appetite suppressants and in $1.9 \%$ of controls (Figure 3 ). The pooled relative risk ratio for FDA MR was 1.55 (95\% CI 1.06 to 2.25, p = 0.02 ) with a number needed to harm of 99 ( $95 \%$ CI 44 to 909). There was no evidence of significant heterogeneity.

The effects of variables such as duration of treatment and specific drugs on the risk of valvulopathy, was not consistently reported. Only two of the seven controlled studies evaluated the relationship between duration and valvulopathy - one study found a definite correlation, while the other did not. The remaining five controlled studies did not comment on dose or duration. Similarly, of the seven uncontrolled studies, three suggested that the risk of valvulopathy was linked to dose and/or duration, while two studies reported exactly the opposite. Owing to the small number of available studies and the lack of individual patient data, we believe that it would not be methodologically sound to draw any conclusions from subgroup analysis of dose, duration or type of drug therapy.

\section{Discussion}

In this systematic overview, we present evidence from three different types of study on the link between appetite suppressants and valvular heart disease. Uncontrolled 
Table 2: Characteristics of uncontrolled echocardiographic studies included in analysis

\begin{tabular}{|c|c|c|c|c|c|c|c|c|}
\hline Author & Year & Patient selection & Drugs used & $\begin{array}{l}\text { Mean } \\
\text { duration } \\
\text { (days) }\end{array}$ & $\begin{array}{l}\text { Blinding of outcome } \\
\text { assessment }\end{array}$ & Total & $\begin{array}{l}\text { FDA } \\
\text { AR }\end{array}$ & $\begin{array}{l}\text { FDA } \\
\text { MR }\end{array}$ \\
\hline Burger [4] & 2001 & $\begin{array}{l}343 / 59 \text { I participants of open- } \\
\text { label study via postal invitation }\end{array}$ & $\begin{array}{l}\text { Combination of fenflu- } \\
\text { ramine-phentermine }\end{array}$ & 370 & $\begin{array}{l}\text { Performed } \\
\text { unblinded, reviewed } \\
\text { on tape by two inde- } \\
\text { pendent readers }\end{array}$ & 343 & $\begin{array}{l}19 \\
(6 \%)\end{array}$ & $3(1 \%)$ \\
\hline FDA [2] & 1997 & $\begin{array}{l}\text { Some convenience, some ran- } \\
\text { dom. Prevalence survey across } \\
\text { five clinics in USA where obese } \\
\text { patients were treated }\end{array}$ & $\begin{array}{l}\text { Fenfluramine, dexfenflu- } \\
\text { ramine, and/or phentermine }\end{array}$ & $\begin{array}{l}\text { Median } \\
420\end{array}$ & None & 284 & $\begin{array}{l}80 \\
(28 \%)\end{array}$ & $\begin{array}{l}18 \\
(6 \%)\end{array}$ \\
\hline Fisher [5] & 1998 & $\begin{array}{l}\text { Consecutive patients with his- } \\
\text { tory of appetite suppressants } \\
\text { referrred for echocardiography }\end{array}$ & $\begin{array}{l}\text { Combination of fenflu- } \\
\text { ramine-phentermine }\end{array}$ & $\begin{array}{l}\text { Not } \\
\text { stated }\end{array}$ & None & 156 & $\begin{array}{l}29 \\
(19 \%)\end{array}$ & $4(3 \%)$ \\
\hline $\begin{array}{l}\text { Kancherla } \\
\text { [6] }\end{array}$ & 1999 & $\begin{array}{l}\text { Consecutive patients with his- } \\
\text { tory of appetite suppressant use } \\
\text { referred for echo study }\end{array}$ & $\begin{array}{l}\text { Fenfluramine, dexfenflu- } \\
\text { ramine and/or phentermine }\end{array}$ & 307 & None & 200 & $\begin{array}{l}24 \\
(12 \%)\end{array}$ & $\begin{array}{l}10 \\
(5 \%)\end{array}$ \\
\hline Lepor [7] & 2000 & $\begin{array}{l}\text { Consecutive patients with his- } \\
\text { tory of appetite suppressant use } \\
\text { referred for echocardiography }\end{array}$ & $\begin{array}{l}\text { Combination of fenflu- } \\
\text { ramine-phentermine }\end{array}$ & 321 & $\begin{array}{l}\text { Blinded readers with } \\
2 \text { nd independent } \\
\text { assessment }\end{array}$ & 85 & $\begin{array}{l}24 \\
(28 \%)\end{array}$ & $\begin{array}{l}9 \\
(11 \%)\end{array}$ \\
\hline $\begin{array}{l}\text { Teramae } \\
{[8]}\end{array}$ & 2000 & $\begin{array}{l}\text { Retrospective review of patients } \\
\text { referred for suspected valve dis- } \\
\text { ease }\end{array}$ & $\begin{array}{l}\text { fenfluramine, dexfenflu- } \\
\text { ramine and/or phentermine }\end{array}$ & 245 & None & 191 & $\begin{array}{l}55 \\
(29 \%)\end{array}$ & $\begin{array}{l}12 \\
(6 \%)\end{array}$ \\
\hline \multirow[t]{2}{*}{$\begin{array}{l}\text { Wadden } \\
\text { [9] }\end{array}$} & 1998 & $\begin{array}{l}20 \text { of } 26 \text { participants in open- } \\
\text { label trial }\end{array}$ & $\begin{array}{l}\text { Combination of fenflu- } \\
\text { ramine-phentermine }\end{array}$ & 730 & $\begin{array}{l}\text { Two independent } \\
\text { readers, blinded to } \\
\text { clinical status }\end{array}$ & 20 & $\begin{array}{l}5 \\
(25 \%)\end{array}$ & $\begin{array}{l}2 \\
(10 \%)\end{array}$ \\
\hline & & & & & Total & 1279 & $\begin{array}{l}236 \\
(18 \%)\end{array}$ & $\begin{array}{l}58 \\
(5 \%)\end{array}$ \\
\hline
\end{tabular}

echocardiographic surveys yield high rates of valvulopathy with over $20 \%$ of patients affected. However, controlled echocardiographic studies show that the attributable rate of valvular heart disease is actually much lower, at less than $6 \%$. No cases of valvulopathy attributable to the drugs were reported in published randomized, controlled trials of appetite suppressants. These differences in the findings are intriguing and merit further discussion.

There are several methodological issues that lead us to question the relatively high rates of valvulopathy found in uncontrolled echocardiographic studies. These studies are at particular risk of detection bias owing to the difficulties in concealing the nature of the study from the outcome assessors (although two studies did attempt to use blinded readers $[7,9])$. The following factors appear to contribute to the detection of high rates of valvulopathy.[3,17] Echocardiographers aware of the possible link between valvulopathy and appetite suppressant use may have persevered in searching for, or highlighting, specific valvular lesions when performing and reviewing the scans. Similarly, such subconscious preconceived notions may have led to bias when interpreting semi-quantitative guidelines - for example, in an obese patient, regurgitation of mild to moderate severity could have been subconsciously classified as moderate in severity. Finally, echocardiographers may have specifically set the technical parameters of the machine to highlight the size and penetration of regurgitant jets.

The design of the uncontrolled studies, with particular regard to case selection, may have undermined the value of the findings. We could not be confident, given the design of the seven uncontrolled studies, that that the patients evaluated were in any way representative of the exposed population. Several methods were used to identify patients - including random samples, convenience samples, and case note reviews of patients referred to an echocardiographic centre. Biases arising from patient selection may have led to high rates of valvulopathy - for example, those specially referred for assessment at echocardiographic centres may have been at particularly high risk of valvular disease.

In contrast, the controlled studies were larger and methodologically more rigorous. Most of the participants and their controls were either part of double-blind randomized controlled trials or were identified from prescrip- 
Table 3: Characteristics of cohort-controlled echocardiographic studies included in analysis

\begin{tabular}{|c|c|c|c|c|c|}
\hline Author & Year & Patient selection & $\begin{array}{l}\text { Ascertainment of } \\
\text { drug exposure }\end{array}$ & Mean duration (days) & $\begin{array}{l}\text { Blinding of outcome assess- } \\
\text { ment }\end{array}$ \\
\hline Gardin [10] & 2000 & $\begin{array}{l}\text { Recruited by physicians } \\
\text { known to be frequent } \\
\text { prescribers }-25 \text { cen- } \\
\text { tres. Controls from } \\
\text { same centres }\end{array}$ & $\begin{array}{l}\text { Medical records } \\
\text { and interview - } \\
\text { dexfenfluramine, } \\
\text { or combination of } \\
\text { fenfluramine-phen- } \\
\text { termine }\end{array}$ & 252 & $\begin{array}{l}\text { Performed blind, tapes } \\
\text { read blind at central labo- } \\
\text { ratory }\end{array}$ \\
\hline Hensrud [II] & 1999 & $\begin{array}{l}\text { Patients from double- } \\
\text { blind randomized con- } \\
\text { trolled trial }\end{array}$ & $\begin{array}{l}\text { In trial of fenflu- } \\
\text { ramine-phenter- } \\
\text { mine }\end{array}$ & 284 & Blinded reviewer \\
\hline Jollis [12] & 2000 & $\begin{array}{l}\text { Prescription registry } \\
\text { data for } 33 \text { practices, } \\
\text { controls from same } \\
\text { centres }\end{array}$ & $\begin{array}{l}\text { Prescription regis- } \\
\text { try - fenfluramine- } \\
\text { phentermine } \\
\text { together }\end{array}$ & 337 & Blinded reviewer \\
\hline Khan [13] & 1998 & $\begin{array}{l}\text { Participated in drug } \\
\text { study at medical cen- } \\
\text { tre, controls from } \\
\text { media advert }\end{array}$ & $\begin{array}{l}\text { Medical records } \\
\text { and self-reports - } \\
\text { dexfenfluramine, } \\
\text { fenfluramine or } \\
\text { phentermine. }\end{array}$ & 615 & $\begin{array}{l}67 \text { unblinded; others per- } \\
\text { formed blind }\end{array}$ \\
\hline Shively [14] & 1999 & $\begin{array}{l}\text { Recruited by prescrib- } \\
\text { ers at } 26 \text { centres; con- } \\
\text { trols were obese } \\
\text { patients at same cen- } \\
\text { tres with no drugs for } \\
5 \text { years }\end{array}$ & $\begin{array}{l}\text { Medical records - } \\
\text { dexfenfluramine }\end{array}$ & 207 & $\begin{array}{l}\text { Blinded and told not to dis- } \\
\text { cuss medication history }\end{array}$ \\
\hline Wee [15] & 1998 & $\begin{array}{l}46 / 76 \text { patients with } \\
\text { previous echo from } \\
\text { two academic centres; } \\
\text { patients acted as their } \\
\text { own controls }\end{array}$ & $\begin{array}{l}\text { Medical records - } \\
\text { dexfenfluramine or } \\
\text { fenfluramine }\end{array}$ & Median 160 & $\begin{array}{l}\text { Performed unblinded; } \\
\text { reread in blinded manner } \\
\text { by one of two readers }\end{array}$ \\
\hline Weissman [16] & 1998 & $\begin{array}{l}1072 / 1212 \text { patients } \\
\text { from double-blind ran- } \\
\text { domized controlled } \\
\text { trial }\end{array}$ & $\begin{array}{l}\text { In a trial of dexfen- } \\
\text { fluramine }\end{array}$ & 71 & $\begin{array}{l}\text { Double blinding of trial } \\
\text { maintained }\end{array}$ \\
\hline
\end{tabular}

tion registry data. All the studies attempted to conceal the treatment group from the outcome assessors. The importance of such blinding is amply illustrated by Khan's study, which started off as an unblinded study but later became a blinded controlled study.[13] Rates of valvulopathy were in excess of $30 \%$ in the first 67 participants evaluated without blinding, but fell to only $19 \%$ after blinding of the primary reader was introduced.[3] Interestingly, the control patients in Khan's study had a very low rate of FDA AR (1.3\%) compared with the controls in other studies in which FDA AR ranged from $2.1 \%$ to $10.9 \%$, with a mean of $3.8 \%$. This may reflect failure of blinding, or a difference in the selection process used in Khan's study in which controls did not come from the same medical centres but were recruited later through media advertisements. These methodological differences would explain why there is heterogeneity of the data, and justify our decision to perform the final meta-analysis for FDA AR without Khan's study.
The relatively high rates of valvulopathy found in the uncontrolled studies may therefore be partly explained by case selection and detection bias. However, the higher rates of valvulopathy in uncontrolled studies (and also in Khan's cohort) may also have been due to the longer duration of drug exposure in these patients, a mean of 310 days compared with 266 days in the controlled studies. Similarly, reversibility of the valvular lesions after cessation of treatment may explain why the uncontrolled surveys, being the earliest ones, yielded the highest rates. In contrast, some of the patients in the later controlled studies had not taken treatment for several months. Nonetheless, the relative rate of regression seems to be less than 10-20\% per annum, and cannot completely account for the large differences between controlled and uncontrolled studies.[18,19]

Such differences are not surprising. Unreliable estimates of the magnitude of treatment effects can arise from small 


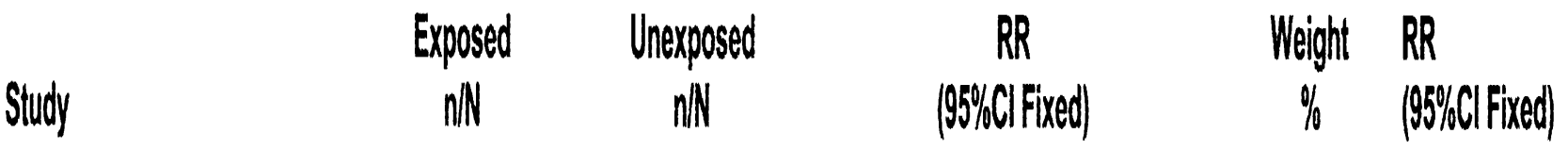

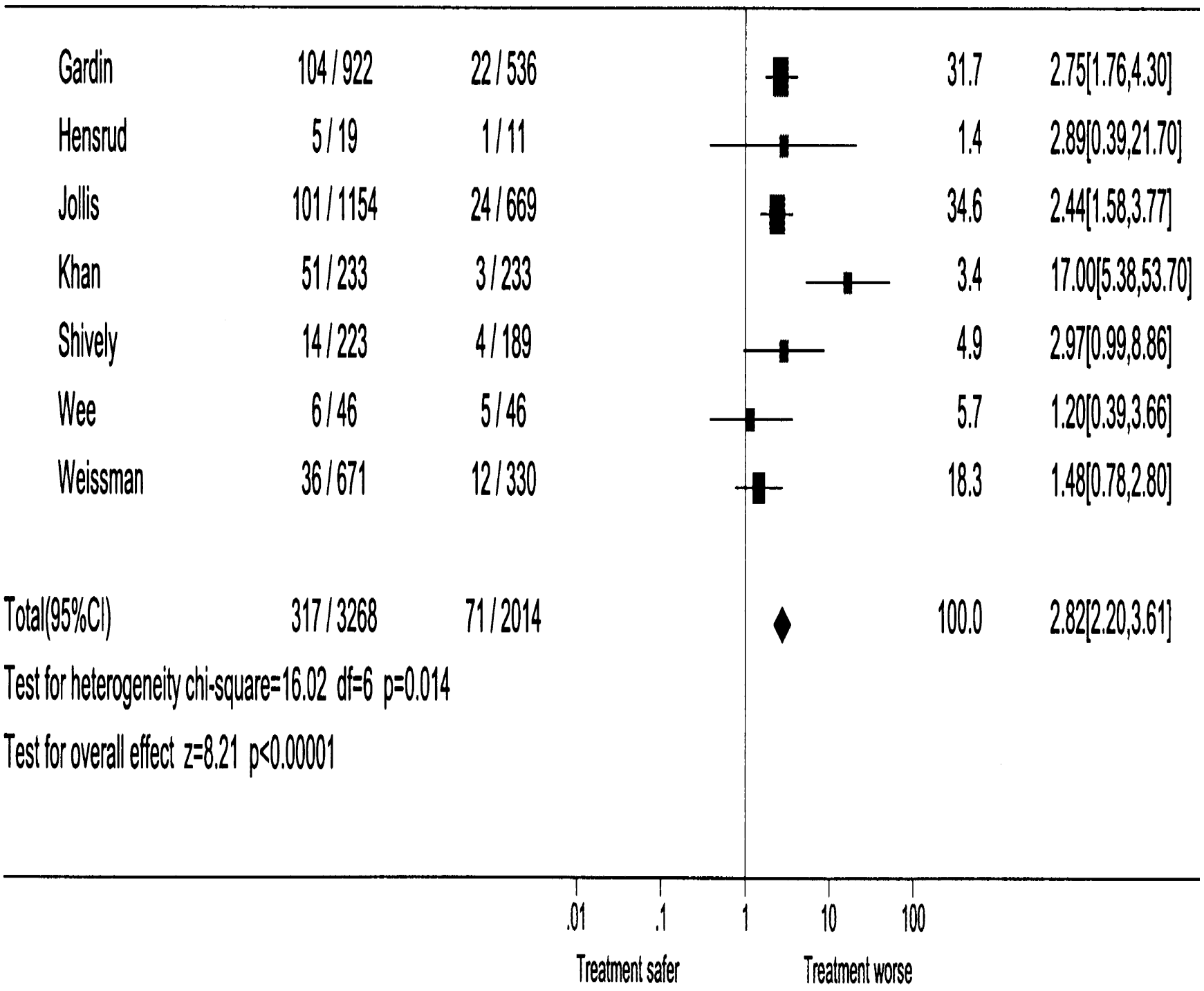

Figure I

Relative risks for FDA AR with appetite suppressants.

studies simply because of random variation.[20] Furthermore, exaggerated treatment effects are more likely to be seen in studies with methodological weaknesses, such as lack of blinding. $[21,22]$ Our findings amply illustrate this. Although decisions on drug safety have often depended on case reports and uncontrolled observations, [23] our results suggest that there can be significant problems in using such data. There is a definite danger that useful drugs may be cast aside prematurely following "knee-jerk" reactions to safety scares founded on poor evidence. We strongly believe that there should be far greater emphasis on using methodologically rigorous studies to generate more precise safety data.

Although systematic echocardiographic assessments were not carried out in the trials, we can still draw useful con- 


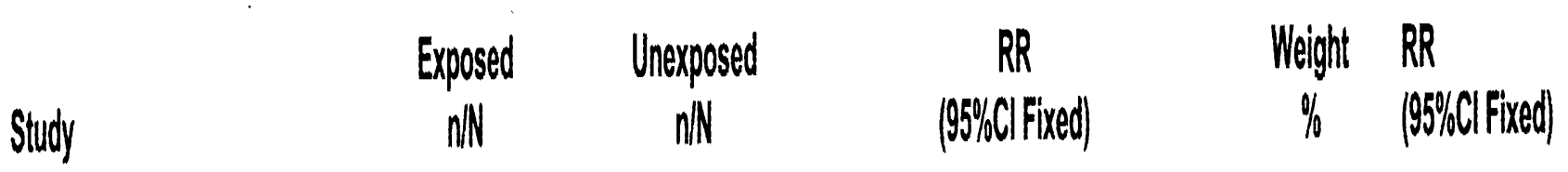

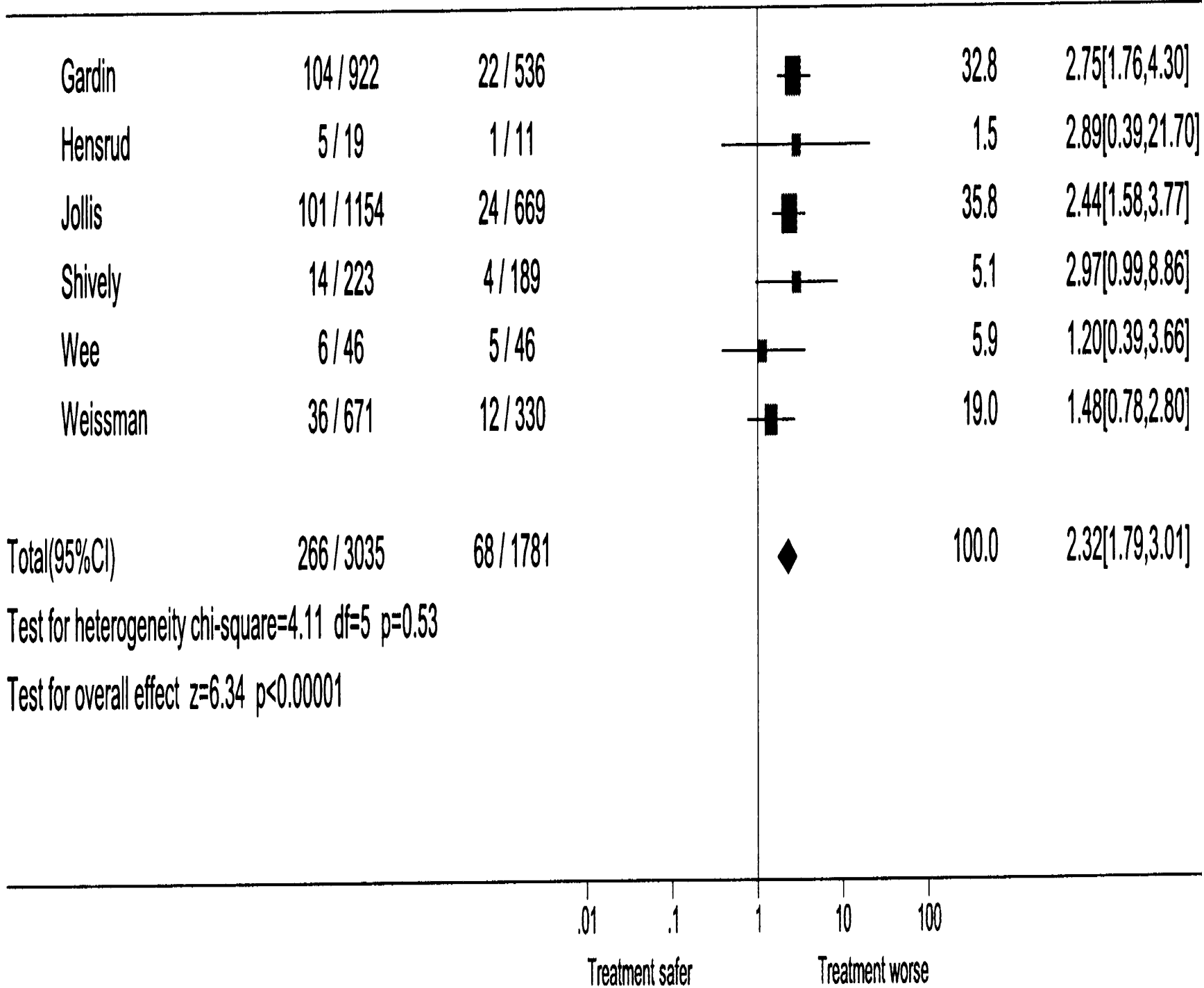

Figure 2

Relative risks for FDA AR with appetite suppressants after exclusion of Khan's study.

clusions from the data. The absence of any clinically diagnosed cases of valvular heart disease in 2907 patients treated over a mean of 17 weeks suggests that the valvulopathy was not of sufficient severity to be found on routine physical examination. Any symptoms must also have been so mild that they were not reported to, or detected by, the investigators. Similarly, a retrospective, population-based study showed that only 11 of 9765 patients
$(0.11 \%)$ taking appetite suppressants had been diagnosed as having valvular heart disease by their physicians.[24] These findings indicate that echocardiographically detectable valvulopathy is often subclinical and may not lead to serious sequelae.[25]

Nonetheless, one cannot help but feel that this debacle could have been avoided altogether if physicians and re- 


$\begin{array}{cccccl} & \text { Exposed } & \text { Unexposed } & \text { RR } & \text { Weight } & \text { RR } \\ \text { Study } & n \mathbb{N} & n N & (95 \% / C \text { F Fixed) } & \% & \text { (955\%Cl Fixed) }\end{array}$

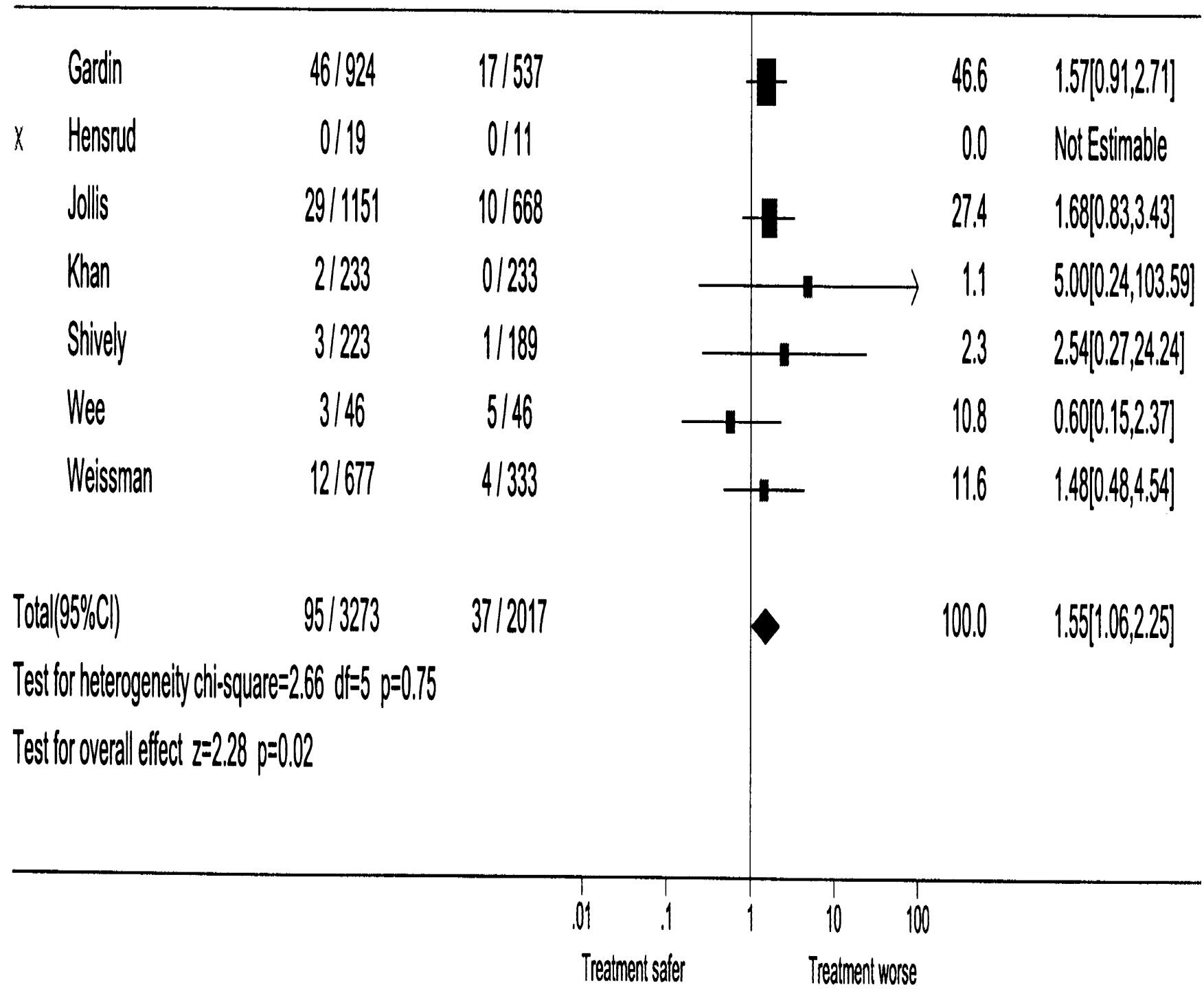

Figure 3

Relative risks for FDA MR with appetite suppressants.

searchers had shown more care. Why wasn't routine echocardiography part of the safety monitoring protocols in the clinical trials, when there had been so much controversy in the past with pulmonary hypertension and appetite suppressants? [26] Furthermore, in view of the lack of comprehensive safety data, prescribers of appetite suppressants should perhaps have attempted to limit the treatment duration (as advised by the regulatory authori- ties) and avoided the use of unlicensed drug combinations. Although it would be far simpler to lay all the blame on the drug itself, there are clearly important lessons here for those involved in evaluating, or prescribing potentially harmful drugs.

Although the risks faced by individual patients (number needed to harm for FDA AR of 20) are much lower than 
originally suggested, it is worth bearing in mind that the drugs could have caused valvulopathy in hundreds of thousands of the six million Americans prescribed the drugs in 1996.[3] Even if severe valvulopathy developed in only a small proportion of those affected, there would still be hundreds of people experiencing serious clinical sequelae.

There are some limitations to this systematic review. We used strict criteria and FDA case-definitions in selecting the studies, and only a limited number were found to be suitable for inclusion in the final analysis. Furthermore, our findings are based on aggregate data from published studies, and we did not have access to individual patient data. We were therefore unable to analyse in detail the effects of variables such as treatment duration, dose, type of drug, and interval between the end of therapy and echocardiography. For example, differences in the rate of valvulopathy among the studies may have been partly accounted for by differences in duration of treatment in the study cohorts. Similarly, exposure to combination therapy, such as the commonly used "phentermine-fenfluramine" combination, may well carry a much higher risk than exposure to phentermine alone. The effects of multiple variables cannot be properly appraised without individual patient data, and are therefore not within the scope of this systematic review.

A final word of warning. Despite withdrawal by the regulatory authorities, sizeable numbers of people may still be consuming these appetite suppressants from other sources such as an unlicensed prescription, or from Chinese herbal preparations. $[27,28]$ As such, the safety information from our analysis continues to be relevant, both to slimmers who are still trying for a cure, and to medical practitioners who may become involved in their care.

\section{Conclusions}

Patients treated with appetite suppressants are at significantly increased risk of developing valvular heart disease. However, the risk of valvulopathy found in this systematic review is much lower than that suggested by initial, less methodologically rigorous studies. We strongly believe that judgements on drug safety should be backed by evidence from high quality sources.

\section{Competing interests}

SD was funded by a research grant from the Sir Jules Thorn Trust.

There are no competing interests.

\section{Authors' contributions}

Contributors: YL conceptualised the review, developed the protocol, provided clinical interpretation of the pa- pers, abstracted data, undertook the statistical analyses and prepared the manuscript. SD contributed to the development of the protocol, abstracted data and revised the manuscript. APC identified papers, abstracted data, reviewed the protocol and helped with the manuscript.

All authors read and approved the final manuscript.

\section{Acknowledgements}

Thanks go to Jeff Aronson for his helpful comments on the manuscript.

\section{References}

I. Connolly HM, Crary JL, McGoon MD, Hensrud DD, Edwards BS, Edwards WD, Schaff HV: Valvular heart disease associated with fenfluramine-phentermine. N Engl J Med 1997, 337:581-588

2. Cardiac valvulopathy associated with exposure to fenfluramine or dexfenfluramine: US Department of Health and Human Services interim public health recommendations, November 1997. MMWR Morb Mortal Wkly Rep 1997, 46:106I1066

3. Schiller NB: Fen/phen and valvular heart disease: if it sounds too bad to be true, perhaps it isn't. J Am Coll Cardiol 1999, 34: I I59- I I 62

4. Burger AJ, Charlamb MJ, Singh S, Notarianni M, Blackburn GL, Sherman HB: Low risk of significant echocardiographic valvulopathy in patients treated with anorectic drugs. Int J Cardiol 2001 , 79:159-165

5. Fisher EA, Ruden R: Pulmonary artery pressures and valvular lesions in patients taking diet suppressants. Cardiovasc Rev Rep 1998, 19:13-16

6. Kancherla MK, Salti HI, Mulderink TA, Parker M, Bonow RO, Mehlman DJ: Echocardiographic prevalence of mitral and/or aortic regurgitation in patients exposed to either fenfluraminephentermine combination or to dexfenfluramine. Am J Cardiol 1999, 84: I335-1338

7. Lepor NE, Gross SB, Daley WL, Samuels BA, Rizzo MJ, Luko SP, Hickey $A$, Buchbinder NA, Naqvi TZ: Dose and duration of fenfluramine-phentermine therapy impacts the risk of significant valvular heart disease. Am J Cardiol 2000, 86: I07-I 10

8. Teramae CY, Connolly HM, Grogan M, Miller FA Jr: Diet drug-related cardiac valve disease: the Mayo Clinic echocardiographic laboratory experience. Mayo Clin Proc 2000, 75:456-46 I

9. Wadden TA, Berkowitz RI, Silvestry F, Vogt RA, St John Sutton MG, Stunkard AJ, Foster GD, Aber JL: The fen-phen finale: a study of weight loss and valvular heart disease. Obes Res 1998, 6:278-284

10. Gardin JM, Schumacher D, Constantine G, Davis KD, Leung C, Reid $C L$ : Valvular abnormalities and cardiovascular status following exposure to dexfenfluramine or phentermine/fenfluramine. JAMA 2000, 283: I703-1709

II. Hensrud DD, Connolly HM, Grogan M, Miller FA, Bailey KR, Jensen MD: Echocardiographic improvement over time after cessation of use of fenfluramine and phentermine. Mayo Clin Proc 1999, 74:I191-I197

12. Jollis JG, Landolfo CK, Kisslo J, Constantine GD, Davis KD, Ryan T: Fenfluramine and phentermine and cardiovascular findings: effect of treatment duration on prevalence of valve abnormalities. Circulation 2000, I 0 I:207| -2077

13. Khan MA, Herzog CA, St. Peter JV, Hartley GG, Madlon-Kay R, Dick $C D$, Asinger RW, Vessey JT: The prevalence of cardiac valvular insufficiency assessed by transthoracic echocardiography in obese patients treated with appetite-suppressant drugs. $N$ Engl J Med 1998, 339:713-7/8

14. Shively BK, Roldan CA, Gill EA, Najarian T, Loar SB: Prevalence and determinants of valvulopathy in patients treated with dexfenfluramine. Circulation 1999, 100:2 161-2167

15. Wee CC, Phillips RS, Aurigemma G, Erban S, Kriegel G, Riley M, Douglas PS: Risk for valvular heart disease among users of fenfluramine and dexfenfluramine who underwent echocardiography before use of medication. Ann Intern Med 1998, 1 29:870-874

16. Weissman NJ, Tighe JF Jr, Gottdiener JS, Gwynne JT: An assessment of heart-valve abnormalities in obese patients taking 
dexfenfluramine, sustained-release dexfenfluramine, or placebo. N Engl J Med 1998, 339:725-732

17. Weissman NJ: Appetite suppressant valvulopathy: a review of current data. Cardiovasc Rev Rep 1999, 20: 146-155

18. Weissman NJ, Panza JA, Tighe JF, Gwynne JT: Natural history of valvular regurgitation I year after discontinuation of dexfenfluramine therapy. A randomized, double-blind, placebocontrolled trial. Ann Intern Med 200I, 134:267-273

19. Mast ST, Jollis JG, Ryan T, Anstrom KJ, Crary JL: The progression of fenfluramine-associated valvular heart disease assessed by echocardiography. Ann Intern Med 200I, 134:26I-266

20. Moore RA, Gavaghan D, Tramer MR, Collins SL, McQuay HJ: Size is everything - large amounts of information are needed to overcome random effects in estimating direction and magnitude of treatment effects. Pain 1998, 78:209-216

21. Moher D, Pham B, Jones A, Cook DJ, Jadad AR, Moher M, Tugwell P, Klassen TP: Does quality of reports of randomised trials affect estimates of intervention efficacy reported in meta-analyses? Lancet 1998, 352:609-613

22. Noseworthy JH, Ebers GC, Vandervoort MK, Farquhar RE, Yetisir E, Roberts $R$ : The impact of blinding on the results of a randomized, placebo-controlled multiple sclerosis clinical trial. Neurology 1994, 44:16-20

23. Arnaiz JA, Carné X, Riba N, Codina C, Ribas J, Trilla A: The use of evidence in pharmacovigilance: case reports as the reference source for drug withdrawals. Eur J Clin Pharmacol 200I, 57:89-9।

24. Jick H, Vasilakis C, Weinrauch LA, Meier CR, Jick SS, Derby LE: A population-based study of appetite-suppressant drugs and the risk of cardiac-valve regurgitation. N Engl J Med 1998, 339:719-724

25. Jick $\mathrm{H}$ : Heart valve disorders and appetite-suppressant drugs. JAMA 2000, 283:1738-1740

26. Fishman AP: Aminorex to fen/phen: an epidemic foretold. Circulation 1999, 99:|56-16|

27. British Broadcasting Corporation News: Slimming pill doctor struck off. [http://news.bbc.co.uk/hi/english/uk/wales/ newsid_1634000//634208.stm] I8 June 2002

28. Metcalfe K, Corns C, Fahie-Wilson M, Mackenzie P: Chinese medicines for slimming still cause health problems. BMJ 2002, 324:679

\section{Pre-publication history}

The pre-publication history for this paper can be accessed here:

http://www.biomedcentral.com/1472-6904/2/6/prepub
Publish with BioMed Central and every scientist can read your work free of charge

"BioMedcentral will be the most significant development for disseminating the results of biomedical research in our lifetime."

Paul Nurse, Director-General, Imperial Cancer Research Fund

Publish with BMC and your research papers will be:

- available free of charge to the entire biomedical community

- peer reviewed and published immediately upon acceptance

- cited in PubMed and archived on PubMed Central

- yours - you keep the copyright

Submit your manuscript here:

http://www.biomedcentral.com/manuscript/
BioMedcentral.com editorial@biomedcentral.com 